\title{
Population studies of diamonds from the North Kimberley kimberlite province, northwest Australia
}

\author{
Linda M. Glass ${ }^{1}$, Wayne R. Taylor ${ }^{2,3}$ and Janusz Jakimowicz ${ }^{4}$ \\ ${ }^{1}$ Northern Territory Geological Survey, Darwin, NT 0801, Australia (linda.glass@nt.gov.au), \\ ${ }^{2}$ CMCA, University of Western Australia, WA 6009, Australia (pterodia@bigpond.net.au) \\ ${ }^{3}$ present address: Uramet Minerals Ltd, PO Box 8280, Subiaco East, WA 6008, Australia \\ ${ }^{4}$ North Australian Diamonds Ltd, East Perth, WA 6004, Australia (januszj@nadl.com.au)
}

Diamond populations from the $\sim 820$ Ma old Ashmore and Seppelt kimberlite clusters and from various alluvial sites (Morelli’s Fox, Meteorite, Helga and Beta Creeks) in the North Kimberley province of Western Australia have been characterized by FTIR spectroscopy (Fig. 1). The populations have been defined on the basis of their nitrogen aggregation character which relates to the time-averaged thermal history (expressed by the variable $\mathrm{T}_{\mathrm{NA}}$ ) experienced by the diamonds during their storage period $\left(\mathrm{t}_{\mathrm{MR}}\right)$ in the Earth's mantle. $\mathrm{T}_{\mathrm{NA}}=$ nitrogen aggregation temperature $\left({ }^{\circ} \mathrm{C}\right)$, and $\mathrm{t}_{\mathrm{MR}}=$ mantle residence time (Ga), i.e. time of formation of the diamond less the kimberlite eruption age.

FTIR spectra over the range 4000 to 600 wavenumbers were recorded on over $1000 \sim 1 \mathrm{~mm}$ sized diamonds with a Bruker FTIR microscope. The spectra were background corrected and processed to give nitrogen impurity content and nitrogen defect aggregation state using the methods of Mendelssohn \& Milledge (1995) and Taylor (2004). Corrections were applied for irregular platelet evolution behaviour. Results are displayed on a series of nitrogen aggregation diagrams (a plot of total nitrogen content vs. degree of A to B nitrogen defect centre aggregation); on the diagram a series of $T_{N A}$ isotherm envelopes for $t_{M R}$ values between 1 and $3 \mathrm{Ga}$ are plotted. For the purposes of comparison in this study when specifying $\mathrm{T}_{\mathrm{NA}}$ we have used $\mathrm{t}_{\mathrm{MR}}=1.2 \mathrm{Ga}$, which reflects the Palaeoproterozoic age of the North Australian Craton.

Diamonds were examined from three pipes in the northeast trending Seppelt cluster: Seppelt-1, Seppelt-2 and Seppelt- 5 and from the Ashmore kimberlite to the north. The Seppelt- 2 kimberlite as has a diamond grade in excess of 200 cpht whereas the other kimberlites have grades $<50 \mathrm{cpht}$. The pipes are uneconomic to mine because of their small size (all $<1 \mathrm{ha}$ ).

The Seppelt-1 kimberlite (Figure 2) is dominated by octahedral diamonds of variable $\mathrm{N}$ content with the major $\mathrm{T}_{\mathrm{NA}}$ population at $1200^{\circ} \mathrm{C}$ and lesser populations at $\mathrm{T}_{\mathrm{NA}} 1170$ and $1240{ }^{\circ} \mathrm{C}$. Diamond populations from Seppelt-5 and Ashmore show a similar distribution.

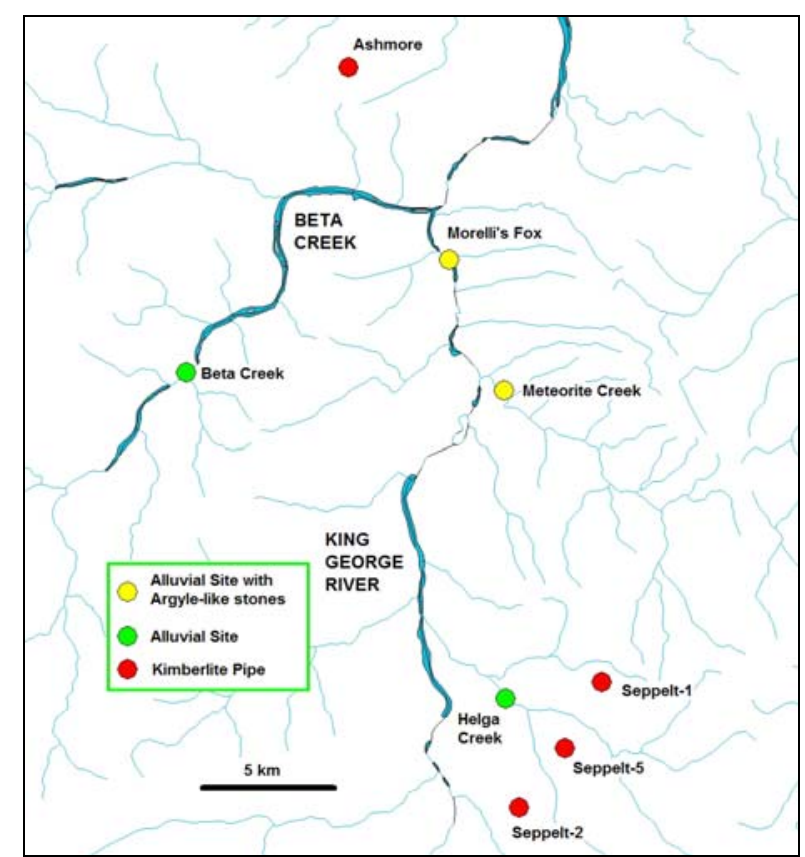

Fig.1 Location of studied sites relative to drainage patterns between the Seppelt and Ashmore kimberlites.

Seppelt-2 also contains the octahedral populations found in the other pipes but in contrast contains a significant dodecahedroid population with $\mathrm{T}_{\mathrm{NA}} \sim 1175$ ${ }^{\circ} \mathrm{C}$ and $\mathrm{N}$ contents mostly $>500 \mathrm{ppm}$ (Figure 3 ); there are lesser dodecahedroid populations at $\mathrm{T}_{\mathrm{NA}}<1170{ }^{\circ} \mathrm{C}$. The horizontal trend shown by the dodecahedroid diamonds on Fig. 3 suggests that this diamond type was derived from much of the shallower mantle column or alternatively, that the $\mathrm{T}_{\mathrm{NA}} \sim 1175{ }^{\circ} \mathrm{C}$ population has been overgrown by younger type IaA diamond, i.e. shows a multiple growth history. Stable isotope measure on diamonds from the $\mathrm{T}_{\mathrm{NA}} \sim 1175{ }^{\circ} \mathrm{C}$ population give $\delta^{13} \mathrm{C}$ values between -4.9 and -6.0 per mil (average -5.6 per mil, $n=6$ ) which are typical of upper mantle peridotitic diamonds. It is apparent that the dodecahedroid populations are responsible for the higher grades and also the higher diamond values found at Seppelt-2. 


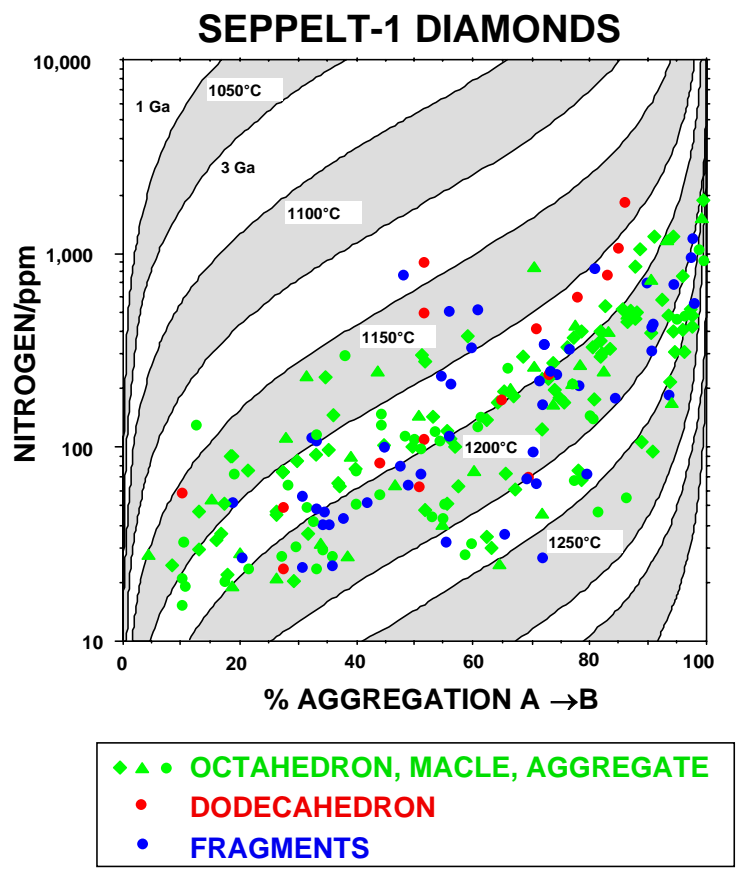

Fig.2 Nitrogen aggregation diagram for diamonds from the Seppelt-1 pipe.

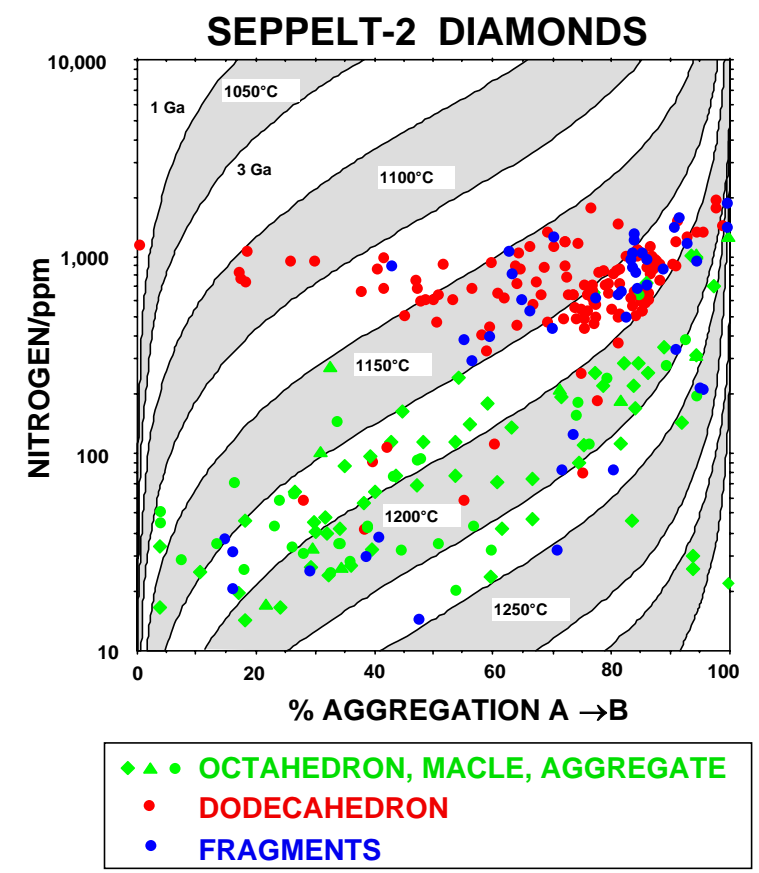

Fig.3 Nitrogen aggregation diagram for diamonds from the Seppelt- 2 pipe; note the dodecahedroid populations dominated by $\mathrm{T}_{\mathrm{NA}} \sim 1175^{\circ} \mathrm{C}$ and $\mathrm{N}>500$ ppm stones.

Diamond populations from the alluvial sites contain recognizable populations sourced from upstream kimberlites (Figure 4). For example Helga Creek and Morelli's Fox clearly contain stones sourced from Seppelt-2. The Beta Creek and Meteorite Creek sites contain Seppelt-1 and Ashmore-like populations suggesting they may have been sourced from as yet undiscovered kimberlite fissure extensions trending southwest-northeast from the known kimberlite clusters. However, there are several significant diamond populations present that do not occur in the known local kimberlites. These include:

- a distinct Type IaA population with $\mathrm{T}_{\mathrm{NA}}<1100{ }^{\circ} \mathrm{C}$ mainly from Beta Creek and Morelli’s Fox sites

- a distinct 'Argyle-like' Type IaB dodecahedroid population with $\mathrm{T}_{\mathrm{NA}}>1250{ }^{\circ} \mathrm{C}$ and hexagonal etch pits and frosting; these are best recognized at the Morelli's Fox and Meteorite Creek alluvial sites

- one unusual diamond containing high-pressure liquid $\mathrm{CO}_{2}$ from Meteorite Creek (Fig. 5).

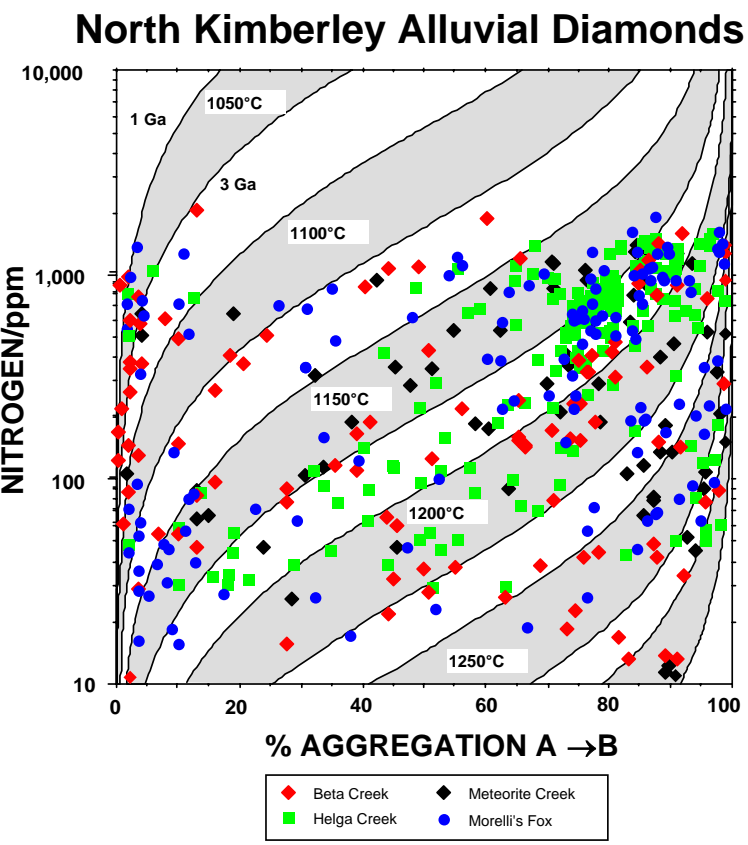

Fig.4 Nitrogen aggregation diagram for alluvial diamonds from various sites (see Fig.1).

It is of exploration interest that the alluvial sites contain a number of diamond populations absent from the known kimberlites suggesting further, undiscovered primary sources exist in the North Kimberley region.

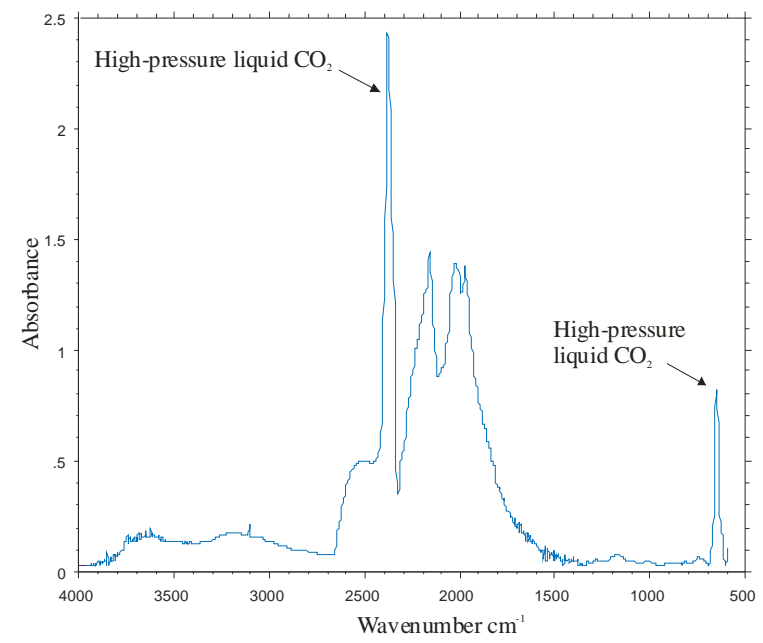

Fig.5 Low-nitrogen content alluvial diamond (S46_13) from Meteorite Creek showing IR absorption bands due to the presence of liquid $\mathrm{CO}_{2}$ at pressure. 
Argyle-like diamonds have previously been recognized from the King George River (Sobelov et al., 1989). In this study we can also confirn an Argyle-like stable isotope signature: measurements on five diamonds with Argyle-like morphological features from Meteorite Creek gave $\delta^{13} \mathrm{C}$ values between -6.9 and -11.5 per mil (average -9.8 per mil) typical of Argyle eclogitic diamonds. It is unclear whether the Argyle-like diamonds in the North Kimberley have somehow been transported hundreds of kilometres from the Argyle pipe (they show no signs of extensive alluvial travel) or whether they are derived from a more proximal source unrelated to Argyle.

In conclusion, even in small kimberlite clusters such as the Seppelt pipes that must have sampled essentially the same upper mantle material, distinct diamond populations may be present in one pipe and not in others. This is presumably the result of significant mantle heterogeneities. As in the case of Seppelt-2 such distinct populations can contribute substantially to diamond grade and in general could make the difference between an economic and a sub-economic prospect.

Diamond populations defined by IR spectroscopy can be traced from primary kimberlite sources to alluvial sites. The presence of unknown populations in alluvial systems points to potential undiscovered primary diamond sources. In combination with morphological and optical sudies, FTIR-defined diamond population studies could be used to trace such sources.

\section{References}

Mendelssohn MJ \& Milledge HJ (1995) International Geology Review, 37, 95-110.

Sobolev NV, Galimov EM, Smith CB, Yefimova ES, Maltsev KA, Hall AE \& Usova LV (1989) Soviet Geology and Geophysics, 30, 1-49.

Taylor WR (2004) Rough Diamond Review, 4, 40-42. 